\title{
Rinite alérgica pela acupuntura e medicina tradicional chinesa
}

\section{Allergic rhinitis by acupuncture and traditional Chinese medicine}

\section{André Wan Wen Tsai}

\section{Caso Clínico}

ID: CDG, sexo feminino, 38 anos.

QD: rinorréia e obstrução nasal há 20 anos.

HMA: apresenta secreção nasal de coloração clara de moderada quantidade diariamente intercalada com períodos de obstrução nasal e respiração bucal. Refere piora com alterações climáticas (frio), pó, mofo e estresse. Melhora com atividade física e medicação (nafazolina + dexametasona + neomicina).

ISDA: facilmente sente cansaço. Perfil mais pessimista e desmotivada.

AP: Tabagista há 10 anos (1 maço/15 dias) sem piora do quadro. Realizou uma rinoplastia (correção de septo) há 5 anos sem melhora dos sintomas. Nega dermatites ou asma.

AF: tia com rinite alérgica e bronquite

EF: Pulso fino, fraco. Língua com revestimento branco, marca de dente, ponta vermelha.

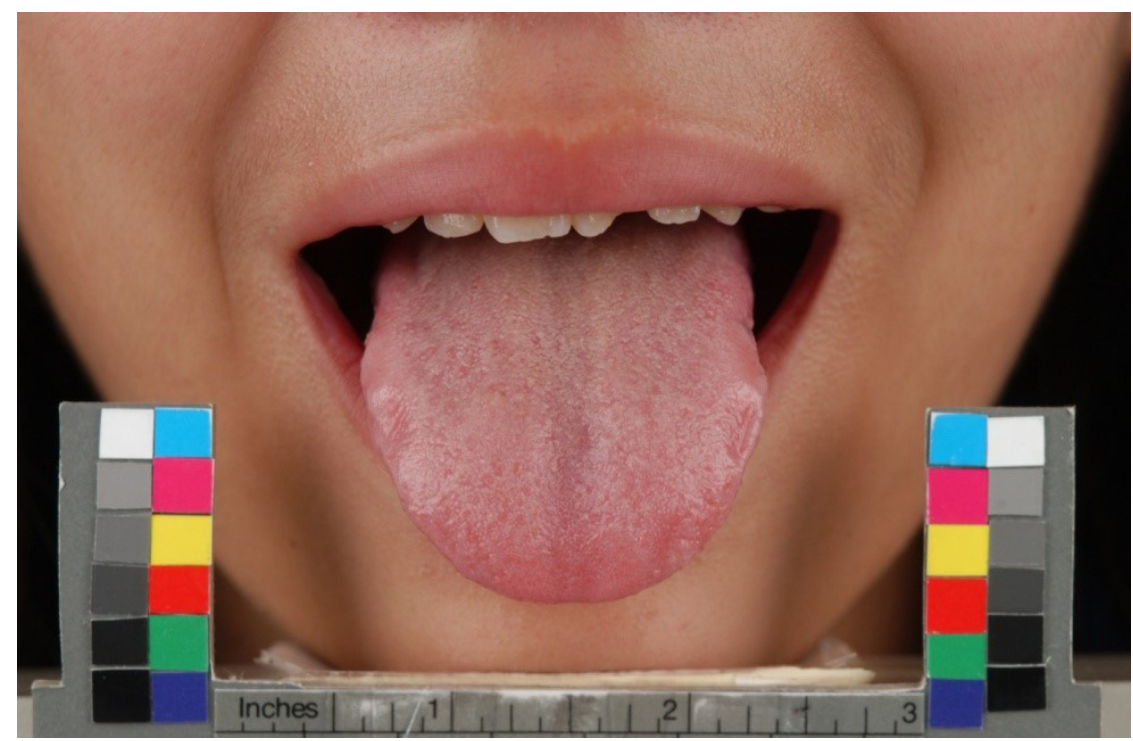

Centro de Acupuntura do IOT- HCFMUSP.

Endereço para correspondência: André W. W. Tsai. Rua Cincinato Braga, 59 - Térreo. São Paulo, SP. CEP: 01333-011. e-mail: tsai.andre@gmail.com 
Tsai AWW. Rinite alérgica pela acupuntura e medicina tradicional chinesa.

\section{Abordagem pela MTC}

O diagnóstico pela Medicina Tradicional Chinesa (MTC) envolve a compreensão do estado geral do paciente frente ao agressor ou fator etiológico da doença. Para isso utilizamos os “4 Métodos de Diagnóstico" pela MTC que engloba a inspeção da face e língua, ausculta/olfação, anamnese e palpação do organismo, o que inclui a palpação do pulso radial. Para esta paciente o diagnóstico pela MTC é a deficiência do Pulmão (Fei) em consequência da invasão do Vento-Frio de longa data.

O Vento-Frio tem como característica causar coriza de secreção clara, espirros, prurido e congestão nasal. A

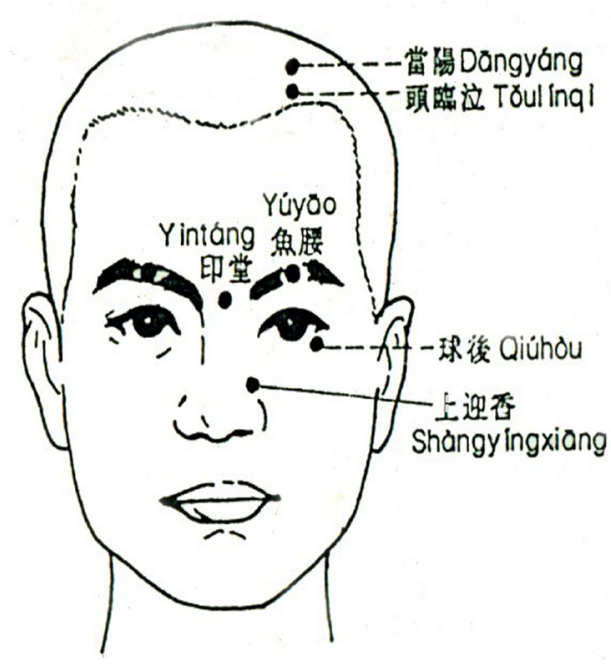

\section{Bi-Tong - Extra HN8}

Localizado no ponto final superior da linha nasolabial.

Agulhamento oblíquo p/ cima ou p/ dentro, 0,3 a 0,5 sensação de cansaço crônico associado à presença de marca de dente na língua e um pulso radial fino e fraco corroboram para o diagnóstico de uma síndrome do tipo Deficiência pela MTC. De acordo com a Teoria dos 5 Movimentos, o órgão relacionado ao nariz e ao aparelho respiratório é o Pulmão (Fei), portanto neste caso, temos como diagnóstico sindrômico a deficiência do Fei.

O princípio de tratamento é dispersar o Vento-Frio e suplementar a deficiência do Pulmão. A seguir as sugestões de pontos de acupuntura que podem ser utilizados em conjunto com a moxabustão com o objetivo de expelir o Frio.

Pontos de Acupuntura: LI-20, Ex- HN3, Ex-HN8, GV-23, LI-4, ST-36, LU-9, BL-13.

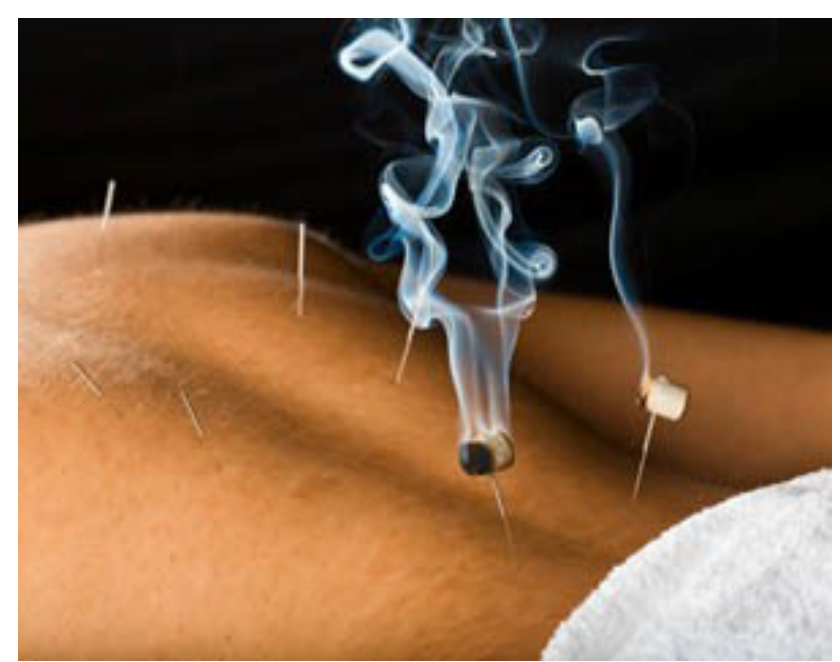

tsun ou em transfixação a partir de Yingxiang (LI 20). Muito eficaz p/ obstrução nasal e diminuição de olfato. 